\title{
High-sensitivity shortwave infrared photodetectors of metal-organic frameworks integrated on 2D layered materials
}

\author{
Fakun Wang, Jie Wu, Yue Zhang, Sijie Yang, Na Zhang, Huiqiao Li and Tianyou Zhai*
}

\begin{abstract}
Photodetectors operating in the shortwave infrared region are of great significance due to their extensive applications in both commercial and military fields. Narrowbandgap two-dimensional layered materials (2DLMs) are considered as the promising candidates for constructing nextgeneration high-performance infrared photodetectors. Nevertheless, the performance of 2DLMs-based photodetectors can hardly satisfy the requirements of practical applications due to their weak optical absorption. In the present study, a strategy was proposed to design high-performance shortwave infrared photodetectors by integrating metalorganic frameworks (MOFs) nanoparticles with excellent optical absorption characteristics and 2DLM with high mobility. Further, this study demonstrated the practicability of this strategy in a MOF/2DLM (Ni-CAT-1/ $\left.\mathrm{Bi}_{2} \mathrm{Se}_{3}\right)$ hybrid heterojunction photodetector. Due to the transfer of photo-generated carriers from the MOF to $\mathrm{Bi}_{2} \mathrm{Se}_{3}$, the MOF nanoparticles integrated on the $\mathrm{Bi}_{2} \mathrm{Se}_{3}$ layer can increase the photocurrent by 2-3 orders of magnitude. The resulting photodetector presented a high responsivity of $4725 \mathrm{~A} \mathrm{~W}^{-1}$ and a superior detectivity of $3.5 \times 10^{13}$ Jones at $1500 \mathrm{~nm}$. The outstanding performance of the hybrid heterojunction arises from the synergistic function of the enhanced optical absorption and photogating effect. In addition, the proposed device construction strategy combining MOF photosensitive materials with 2DLMs shows a high potential for the future high-performance shortwave infrared photodetectors.
\end{abstract}

Keywords: shortwave infrared photodetector, 2D layered materials, metal-organic frameworks, hybrid heterojunctions

\section{INTRODUCTION}

Shortwave infrared (SWIR) photodetector is one of the core components in modern electronics industry, which demonstrates a vital role in various fields such as military defense, industrial production, medical diagnosis and optical communication [1-5]. Two-dimensional layered materials (2DLMs) with narrow bandgap and high mobility are considered as the promising candidates for next-generation infrared optoelectronics due to their unique structures and photoelectric properties [6-11]. At present, considerable efforts have been devoted to demonstrating the SWIR photodetection performance of 2DLMs [1,5]. However, most of the 2DLMs-based SWIR pho- todetectors suffer from low responsivity $\left(10^{-3}-10^{1} \mathrm{~A} \mathrm{~W}^{-1}\right)$ due to the intrinsic weak optical absorption induced by their atomically thin nature [5]. In photodetectors, the responsivity $(R)$ is jointly determined by the external quantum efficiency (EQE) and the photoconductivity gain $(G)$ according to the equation of $R=\frac{e \lambda}{h c} \times \mathrm{EQE} \times G$, where $h, c, e$ and $\lambda$ refer to the reduced Planck constant, light velocity, elementary electronic charge and incident wavelength, respectively. EQE is positively correlated with the optical absorption efficiency. As a result, the responsivity can be improved by enhancing optical absorption and introducing high photoconductivity gain. An effective strategy to achieve high responsivity is to combine a strong light absorption layer with high mobility 2DLMs $[9,12]$. In this configuration, the photosensitive layer absorbs photons and generates the electron-hole pairs under illumination. Then, the photo-generated carriers are transferred to the 2DLMs, thus enhancing the responsivity. In the meanwhile, part of the photogenerated carriers (electrons or holes) are captured by the traps or defects in the photosensitive layer and can form a photoinduced localized field (photogating effect). As a result, the carriers can recirculate repeatedly in the 2DLM channel before the recombination, further increasing the responsivity.

Currently, the selected photosensitive layers mainly contain plasmonic nanostructure $[13,14]$, colloidal quantum dots (e.g., $\mathrm{PbS}, \mathrm{PbSe}, \mathrm{HgTe})[12,15,16]$, low-dimensional perovskites [1719], and inorganic nanoparticles [20,21]. For example, the HgTe-sensitized $\mathrm{MoS}_{2}$ photodetector demonstrates an outstanding responsivity on the order of $10^{3} \mathrm{~A} \mathrm{~W}^{-1}$ at a wavelength of $2 \mu \mathrm{m}$ [15]. The hybrid $\mathrm{Ti}_{2} \mathrm{O}_{3}$ nanoparticles/graphene device achieves a high responsivity of $300 \mathrm{~A} \mathrm{~W}^{-1}$ in a broadband wavelength range up to $10 \mu \mathrm{m}$ [20]. Even though these photosensitive materials have been effective on improving the responsivity of 2DLM-based photodetectors, they still have some shortcomings in practical applications. The enhancement of plasmonic nanostructure is limited by its resonant frequency and the toxicity of colloidal quantum dots is harmful to human health. The instability of perovskite limits device applications, and the high dark current of inorganic nanoparticles will generate low detectivity. Therefore, it is of great significance to develop a promising photosensitive material that can overcome the above-mentioned drawbacks.

In the present work, a novel strategy was proposed by utilizing metal-organic frameworks (MOFs) nanoparticles as the photo-

State Key Laboratory of Materials Processing and Die \& Mould Technology, School of Materials Science and Engineering, Huazhong University of Science and Technology, Wuhan 430074, China

* Corresponding author (email: zhaity@hust.edu.cn) 
sensitive materials of 2DLM-based photodetectors. MOFs formed by the coordination of metal ions and organic ligands exhibit highly tailorable bandgap, optical absorbance and electrical conductivity through varying the metal, ligand, and/or the growth conditions [22-28], which can be applied to different situations in line with the requirements of detection bands. Among them, MOF (Ni-CAT-1) possesses a narrow bandgap of $0.48 \mathrm{eV}$ and strong optical absorption in the SWIR region $[29,30]$, making it appropriate to combine with 2DLM to achieve high-performance SWIR photodetection. In addition, the moderate electrical conductivity induced by the high porosity of MOF does not significantly increase the dark current, thus retaining the high detectivity of the device [24,29]. Consequently, we demonstrated the high-sensitivity SWIR photodetectors by hybridizing Ni-CAT-1 nanoparticles with highmobility $2 \mathrm{D} \quad \mathrm{Bi}_{2} \mathrm{Se}_{3}$ flakes, where a high responsivity of $4725 \mathrm{~A} \mathrm{~W}^{-1}$ and a superior detectivity of $3.5 \times 10^{13}$ Jones at $1500 \mathrm{~nm}$ were obtained in the present $\mathrm{Ni}-\mathrm{CAT}-1 / \mathrm{Bi}_{2} \mathrm{Se}_{3}$ hybrid heterojunction. The outstanding performance can be attributed to the synergistic function of the enhanced optical absorption and photogating effect. The obtained results indicate the great potential of combining MOF materials with 2DLMs for highperformance infrared optoelectronic applications.

\section{EXPERIMENTAL SECTION}

\section{Preparation of $2 \mathrm{D} \mathrm{Bi}_{2} \mathrm{Se}_{3}$ flakes}

The $2 \mathrm{D} \mathrm{Bi}_{2} \mathrm{Se}_{3}$ flakes were obtained via van der Waals epitaxial growth in a horizontal single-zone furnace equipped with a quartz tube. $\mathrm{Bi}_{2} \mathrm{Se}_{3}$ powder $(0.2 \mathrm{~g})$ and fresh mica substrate were employed as the precursor and growth substrate, and were placed at the center and the downstream region of the furnace, respectively. The center region was heated up to $600^{\circ} \mathrm{C}$ over $30 \mathrm{~min}$ and maintained at $600^{\circ} \mathrm{C}$ for $45 \mathrm{~min}$ under 80 standard cubic centimeter per minute $(\mathrm{sccm})$ Ar carrier gas flow. Then the furnace was naturally cooled down to room temperature, and then the high-quality $2 \mathrm{D} \mathrm{Bi}_{2} \mathrm{Se}_{3}$ flakes were obtained on the mica substrates.

\section{Synthesis of Ni-CAT-1 nanoparticles}

In this study, $0.01 \times 10^{-3}$ mol HHTP $(2,3,6,7,10,11$-hexahydroxytriphenylene) and $0.05 \times 10^{-3} \mathrm{~mol}$ nickel acetate $\left(\mathrm{Ni}\left(\mathrm{CH}_{3} \mathrm{COO}\right)_{2}\right)$ were dissolved separately in deionized water by sonication to prepare stock solutions. Next, $3 \mathrm{~mL}$ of each stock solution was added into a $20-\mathrm{mL}$ cylindrical pressure vial and Ni-CAT-1 nanoparticles were formed after heating the vial at $85^{\circ} \mathrm{C}$ for $12 \mathrm{~h}$.
Fabrication of 2D $\mathrm{Bi}_{2} \mathrm{Se}_{3} / \mathrm{Ni}-\mathrm{CAT}-1$ hybrid heterojunction device First of all, the as-grown $2 \mathrm{D} \mathrm{Bi}_{2} \mathrm{Se}_{3}$ flakes on mica substrate were transferred onto a silicon wafer with $300 \mathrm{~nm}$ thermalized $\mathrm{SiO}_{2}$ layer by the poly(methyl methacrylate) (PMMA) and poly(propylene carbonate) (PPC)-assisted transfer technique [31]. Afterwards, the $\mathrm{Bi}_{2} \mathrm{Se}_{3}$-based back-gate field-effect transistor was fabricated by the standard electron beam lithography (ELPHY Plus, Raith $\mathrm{GmbH}$ ) and thermal evaporation (Nexdep, Angstrom Engineering). Subsequently, the as-fabricated $\mathrm{Bi}_{2} \mathrm{Se}_{3}$ device was immersed in a mixture of HHTP and $\mathrm{Ni}\left(\mathrm{CH}_{3} \mathrm{COO}\right)_{2}$ stock solution, and the Ni-CAT-1 nanoparticles self-assembled on the surface of $\mathrm{Bi}_{2} \mathrm{Se}_{3}$ flakes after heating at $85^{\circ} \mathrm{C}$ for $12 \mathrm{~h}$. Finally, the $\mathrm{Bi}_{2} \mathrm{Se}_{3} / \mathrm{Ni}$-CAT-1 hybrid heterojunction device was washed with deionized water for several times and annealed at $100^{\circ} \mathrm{C}$ for $10 \mathrm{~min}$ to remove the moisture.

\section{Characterization and measurements}

The phase and structure of the as-synthesized Ni-CAT-1 nanoparticles were determined by a powder X-ray diffractometer (XRD, D2 Phaser, Bruker) and transmission electron microscopy (TEM, Tecnai G2 F30, FEI). The morphology of the as-fabricated $\mathrm{Bi}_{2} \mathrm{Se}_{3} / \mathrm{Ni}$-CAT- 1 hybrid heterojunction was obtained by optical microscopy (BX51, OLYMPUS), atomic force microscopy (AFM, Dimension Icon, Bruker) and scanning electron microscopy (SEM, Quanta 650, FEI). Raman spectra were collected using a confocal microscope spectrometer (Alpha 300R, WITec) equipped with a 532-nm laser. Besides, the optical absorption spectra were recorded on an ultraviolet visible nearinfrared spectrophotometer (SolidSpec-3700, SHIMADZU). The electrical measurements were conducted on a probe station (CRX-6.5K, Lakeshore), which was connected to a semiconductor analyzer (4200-SCS, Keithley). In terms of photodetection, the incident light with a variety of wavelengths was provided by a broadband laser-driven light source (EQ-1500, Energetiq).

\section{RESULTS AND DISCUSSION}

The schematic diagram of the proposed MOF/2DLM (Ni-CAT$1 / \mathrm{Bi}_{2} \mathrm{Se}_{3}$ ) hybrid heterojunction photodetector is displayed in Fig. 1a. It represents the configuration of $2 \mathrm{D} \mathrm{Bi}_{2} \mathrm{Se}_{3}$ channel decorated with Ni-CAT-1 nanoparticles. Ni-CAT-1 exhibits a layered structure (Fig. 1b) and strong light absorption in the near-infrared region. As a result, it can be easily epitaxially grown on the surface of layered $\mathrm{Bi}_{2} \mathrm{Se}_{3}$ flakes and used as an efficient light absorber to enhance the light absorption capacity of the heterojunction device. As shown in Fig. 1c, incident SWIR light was absorbed by the MOF nanoparticles film under illu-
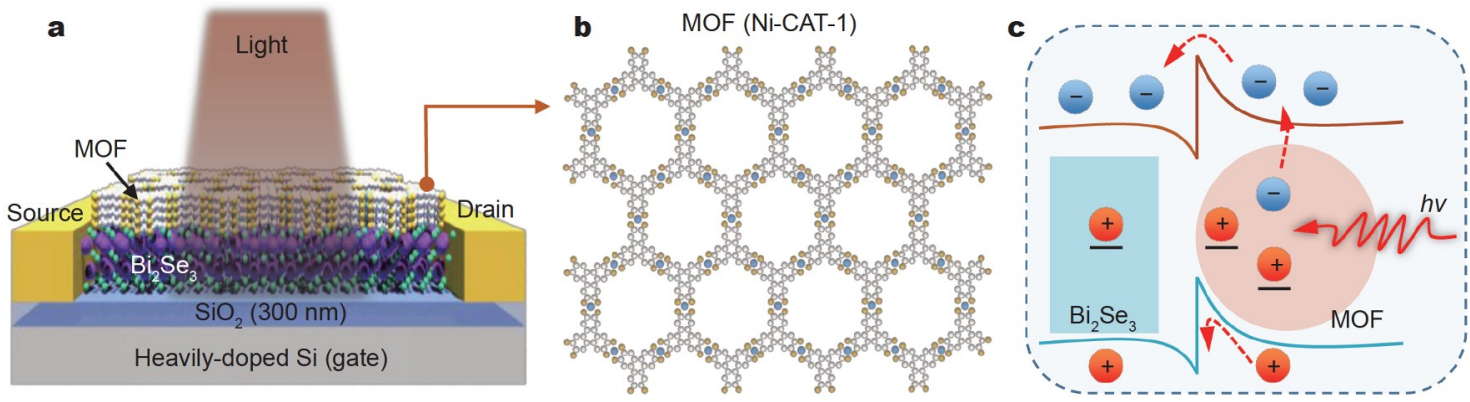

Figure $12 \mathrm{D} \mathrm{Bi}_{2} \mathrm{Se}_{3} / \mathrm{MOF}$ hybrid heterojunction photodetectors. (a) Schematic diagram of the $2 \mathrm{D} \mathrm{Bi} \mathrm{Se}_{3} / \mathrm{MOF}$ hybrid heterojunction. (b) Crystal structure of MOF (Ni-CAT-1). (c) Schematic band diagram of the heterojunction photodetector under illumination. 
mination. At the same time, photo-generated electron-hole pairs were separated at the interface between the MOF and $\mathrm{Bi}_{2} \mathrm{Se}_{3}$. The photo-generated electrons were transferred to the $\mathrm{Bi}_{2} \mathrm{Se}_{3}$ channel to contribute photocurrent. The photo-generated holes remained within the MOF layer as a local gate to regulate the channel conductance, so as to enhance the photoconductivity gain of the device, which thus achieved high performance SWIR photodetection.

The Ni-CAT-1 nanoparticles were synthesized by a simple solution process, in which the HHTP and $\mathrm{Ni}\left(\mathrm{CH}_{3} \mathrm{COO}\right)_{2}$ stock solutions were used as the precursors (Fig. S1a). As shown in the XRD pattern in Fig. 2b, all diffraction peaks were in good consistence with the simulated peaks, indicating that the assynthesized Ni-CAT-1 nanoparticles possessed high purity. Moreover, the small full width at half maximum of the XRD peaks demonstrated the high crystallinity of the as-synthesized Ni-CAT-1 nanoparticles. The high-resolution TEM (HRTEM) image shown in Fig. S1b further confirmed the high crystalline quality of the as-synthesized Ni-CAT-1 nanoparticles. Therefore, the simple solution process was further adopted to prepare the $2 \mathrm{D} \mathrm{Bi}_{2} \mathrm{Se}_{3} / \mathrm{Ni}$-CAT-1 hybrid heterojunctions. As illustrated in Fig. $2 \mathrm{a}$, the $2 \mathrm{D} \mathrm{Bi}_{2} \mathrm{Se}_{3}$-based device prepared before hand was immersed in the mixture of HHTP and $\mathrm{Ni}\left(\mathrm{CH}_{3} \mathrm{COO}\right)_{2}$ stock solutions. After heating at $85^{\circ} \mathrm{C}$ for $12 \mathrm{~h}$, the surface of the $2 \mathrm{D}$
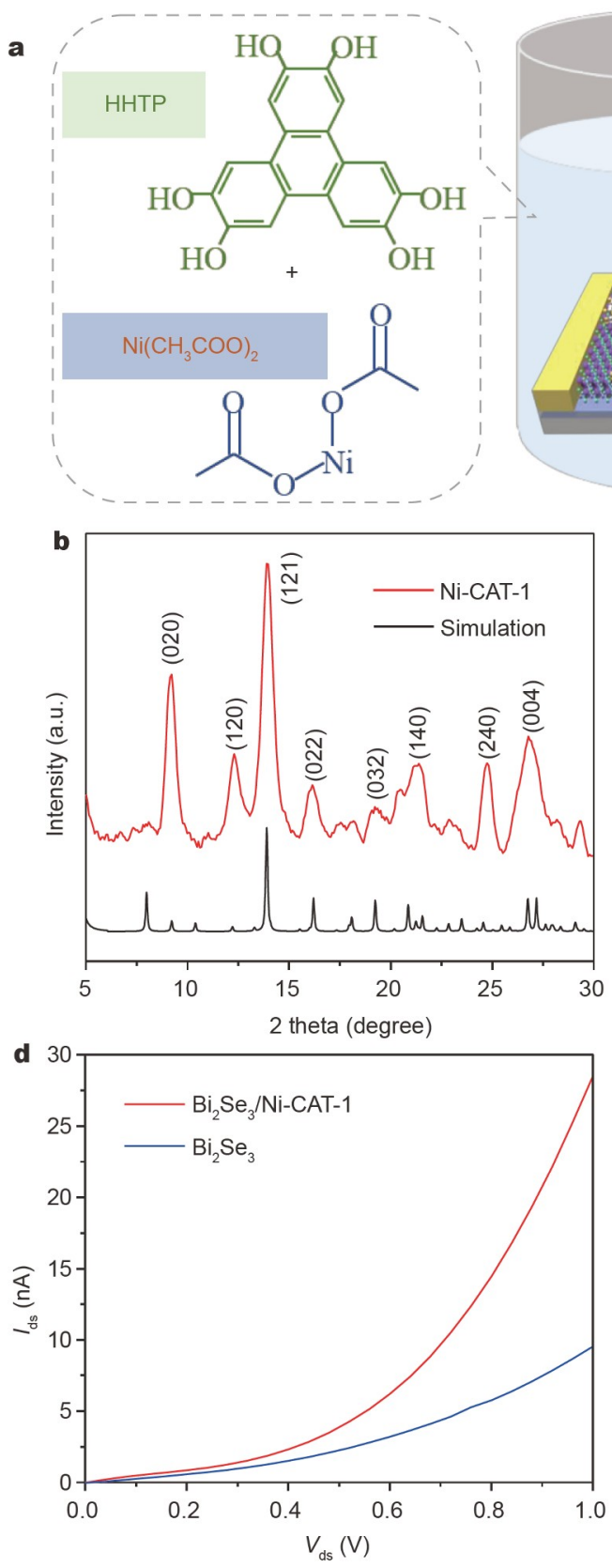
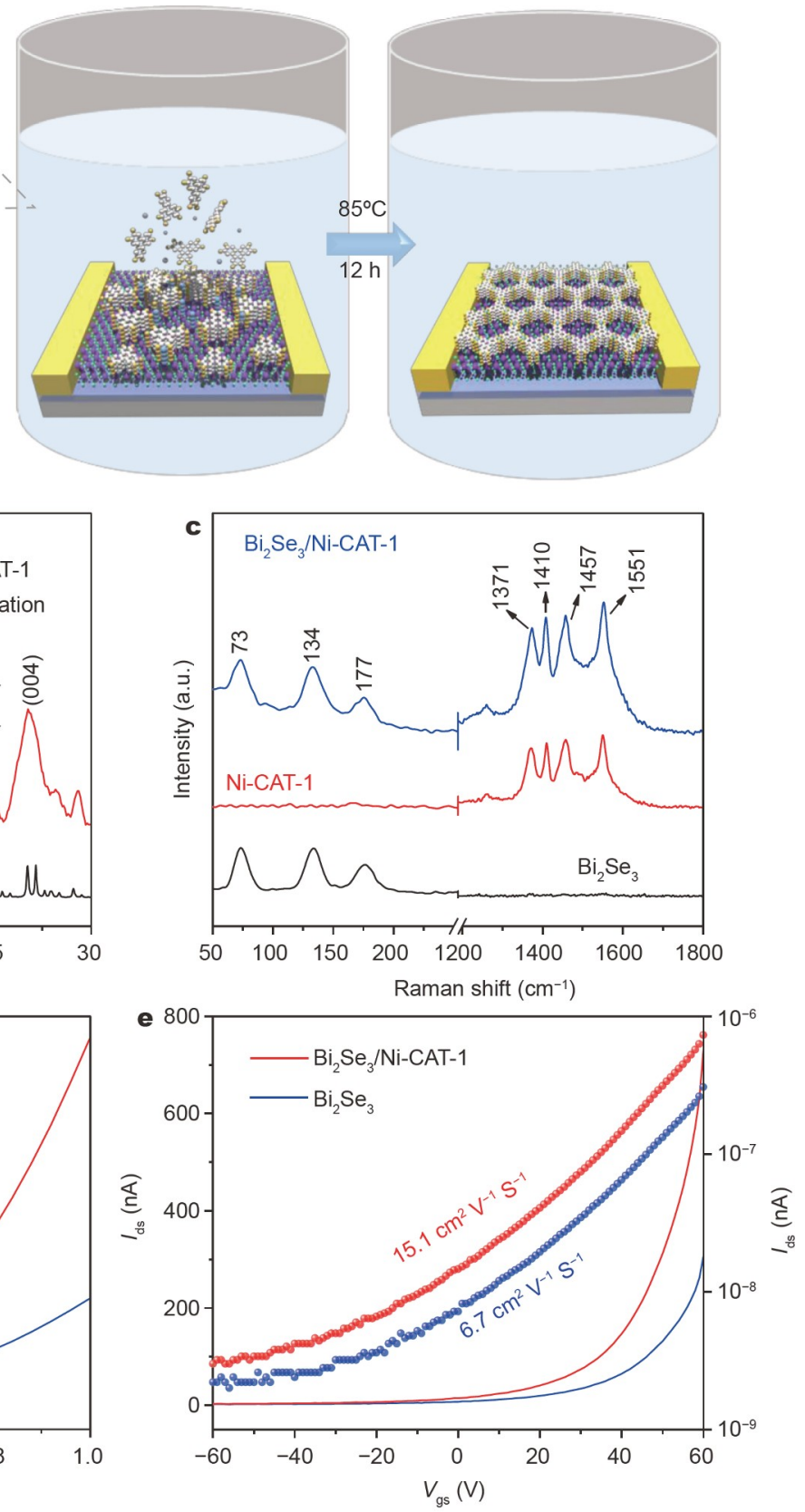

Figure 2 Fabrication and characterization of the $2 \mathrm{D} \mathrm{Bi}_{2} \mathrm{Se}_{3} / \mathrm{Ni}-\mathrm{CAT}-1$ hybrid heterojunction. (a) Epitaxial growth of Ni-CAT-1 nanoparticles on multilayer $\mathrm{Bi}_{2} \mathrm{Se}_{3}$ flakes in a sealed glass tube with ethanol solution. (b) XRD patterns of the as-synthesized Ni-CAT-1 nanoparticles. (c) Raman spectra of the Bi $\mathrm{Se}_{3}$ flake and $\mathrm{Bi}_{2} \mathrm{Se}_{3} / \mathrm{Ni}$-CAT-1 hybrid heterojunction. (d) Output characteristic curves of the pristine $\mathrm{Bi}_{2} \mathrm{Se}_{3}$ and $\mathrm{Bi}_{2} \mathrm{Se}_{3} / \mathrm{Ni}-\mathrm{CAT}-1$ hybrid heterojunction at $V_{\mathrm{gs}}=0 \mathrm{~V}$. (e) Transfer characteristic curves of the pristine $\mathrm{Bi}_{2} \mathrm{Se}_{3}$ and $\mathrm{Bi}_{2} \mathrm{Se}_{3} / \mathrm{Ni}-\mathrm{CAT}-1$ hybrid heterojunction at $V_{\mathrm{ds}}=1 \mathrm{~V}$. 
$\mathrm{Bi}_{2} \mathrm{Se}_{3}$ flakes was covered with a thin film composed of Ni-CAT1 nanoparticles, thus forming the $2 \mathrm{D} \mathrm{Bi}_{2} \mathrm{Se}_{3} / \mathrm{Ni}$-CAT- 1 hybrid heterojunctions. Details concerning the experimental process are provided in the EXPERIMENTAL SECTION. Fig. S2a shows an optical microscopic image of the $2 \mathrm{D} \mathrm{Bi}_{2} \mathrm{Se}_{3}$-based device before and after growing Ni-CAT-1 nanoparticles. Obviously, the morphology and structure of the $2 \mathrm{D} \mathrm{Bi}_{2} \mathrm{Se}_{3}$ channel still maintained its integrity, indicating that the preparation process was relatively mild and did not cause damage to the $2 \mathrm{D} \mathrm{Bi}_{2} \mathrm{Se}_{3}$ channel, which ensured the electrical and optoelectronic measurements of the $2 \mathrm{D} \mathrm{Bi}_{2} \mathrm{Se}_{3} / \mathrm{Ni}-\mathrm{CAT}-1$ hybrid heterojunction devices. The SEM image shown in Fig. S2b indicated that the NiCAT-1 nanoparticles were uniformly covered on the surface of the $2 \mathrm{D} \mathrm{Bi}_{2} \mathrm{Se}_{3}$ flakes. According to Fig. $\mathrm{S} 1 \mathrm{~b}$, the size of these particles was on the order of nanometers. The thickness of the Ni-CAT-1 nanoparticles thin film was determined to be $\sim 140 \mathrm{~nm}$ (Fig. S2b) by AFM. Fig. 2c presents the Raman spectra of the $2 \mathrm{D} \mathrm{Bi}_{2} \mathrm{Se}_{3}$ flakes, Ni-CAT-1 nanoparticles and $\mathrm{Bi}_{2} \mathrm{Se}_{3} / \mathrm{Ni}$ CAT-1 hybrid heterojunctions. Additionally, three peaks located at 73,134 , and $177 \mathrm{~cm}^{-1}$ were found in the $2 \mathrm{D} \mathrm{Bi}_{2} \mathrm{Se}_{3}$ flakes, which were assigned to the $\mathrm{A}_{1 \mathrm{~g}}{ }_{1 \mathrm{~g}} \mathrm{E}_{\mathrm{g}}^{2}$, and $\mathrm{A}^{2}{ }_{1 \mathrm{~g}}$ modes, respectively $[32,33]$. Four peaks at $1371,1410,1457,1551 \mathrm{~cm}^{-1}$ were observed on Ni-CAT-1 nanoparticles, and attributed to the vibrations of $\mathrm{C}-\mathrm{C}$ bonds of HHTP linkers in Ni-CAT-1 [29,34]. Regarding the $\mathrm{Bi}_{2} \mathrm{Se}_{3} / \mathrm{Ni}-\mathrm{CAT}-1$ hybrid heterojunction, the peaks of $\mathrm{Bi}_{2} \mathrm{Se}_{3}$ and Ni-CAT-1 were observed, revealing that the successful combination of the Ni-CAT-1 nanoparticles on the $2 \mathrm{D}$ $\mathrm{Bi}_{2} \mathrm{Se}_{3}$ flakes.

The electrical characteristics of the pristine $2 \mathrm{D} \mathrm{Bi}_{2} \mathrm{Se}_{3}$ flake and 2D $\mathrm{Bi}_{2} \mathrm{Se}_{3} / \mathrm{Ni}$-CAT-1 hybrid heterojunction were measured in the configuration of back-gate field-effect transistor. Fig. $2 \mathrm{~d}$ illustrates the output characteristic curves (drain current, $I_{\mathrm{ds}} v s$. drain voltage, $V_{\mathrm{ds}}$ ) of the $\mathrm{Bi}_{2} \mathrm{Se}_{3}$ and $\mathrm{Bi}_{2} \mathrm{Se}_{3} / \mathrm{Ni}$-CAT-1 hybrid heterojunction in the dark. Obviously, the value of drain current for the $\mathrm{Bi}_{2} \mathrm{Se}_{3} / \mathrm{Ni}$-CAT-1 hybrid heterojunction was higher than that of the pristine $2 \mathrm{D} \mathrm{Bi}_{2} \mathrm{Se}_{3}$ flake. In the meanwhile, the pristine Ni-CAT-1 nanoparticles did not exhibit noticeable electrical conductivity, as shown in Fig. S3. Therefore, the main conducting channel was ascribed to the $2 \mathrm{D}_{2} \mathrm{Be}_{3}$ flake in the $\mathrm{Bi}_{2} \mathrm{Se}_{3} /$ Ni-CAT-1 hybrid heterojunction device. The increased electrical conductivity in the $\mathrm{Bi}_{2} \mathrm{Se}_{3} / \mathrm{Ni}-\mathrm{CAT}-1$ hybrid heterojunction might be caused by the electronic doping of Ni-CAT-1 to $\mathrm{Bi}_{2} \mathrm{Se}_{3}$. In addition, the transfer characteristic curves (drain current, $I_{\mathrm{ds}}$ $v s$. gate voltage, $\left.V_{\mathrm{gs}}\right)$ shown in Fig. 2e also presented an increase in the drain current of the $\mathrm{Bi}_{2} \mathrm{Se}_{3} / \mathrm{Ni}-\mathrm{CAT}-1$ hybrid heterojunction in comparison with that of the pristine $\mathrm{Bi}_{2} \mathrm{Se}_{3}$ device. The log-scale curves in Fig. 2e indicated that the on/off current ratio of the $\mathrm{Bi}_{2} \mathrm{Se}_{3} / \mathrm{Ni}-\mathrm{CAT}-1$ hybrid heterojunction slightly increased from 139 to 244 . The electrical characteristics revealed that the electronic doping effect occurred in the $2 \mathrm{D} \mathrm{Bi}_{2} \mathrm{Se}_{3}$ flake after the combination of the Ni-CAT-1 nanoparticles, which was in accordance with the previously reported results in graphene/ Ni-CAT-1 structure [29]. The field-effect mobility $(\mu)$ of the pristine $2 \mathrm{D} \mathrm{Bi}_{2} \mathrm{Se}_{3}$ flakes and $\mathrm{Bi}_{2} \mathrm{Se}_{3} / \mathrm{Ni}-\mathrm{CAT}-1$ hybrid heterojunction was evaluated by the equation [35]: $\mu=\left(\Delta I_{\mathrm{ds}} / \Delta I_{\mathrm{gs}}\right)(L /$ $\left.W C_{\mathrm{ox}} V_{\mathrm{ds}}\right)$, where $L, W$ and $C_{\mathrm{ox}}$ represent the channel length, width and gate capacitance, respectively. As a result, the fieldeffect mobility of the pristine $\mathrm{Bi}_{2} \mathrm{Se}_{3}$ and $\mathrm{Bi}_{2} \mathrm{Se}_{3} / \mathrm{Ni}-\mathrm{CAT}-1$ hybrid heterojunction was calculated to be 6.7 and $15.1 \mathrm{~cm}^{2} \mathrm{~V}^{-1} \mathrm{~s}^{-1}$, respectively. This enhancement (by $\sim 2$ times) of field-effect mobility in the $\mathrm{Bi}_{2} \mathrm{Se}_{3} / \mathrm{Ni}$-CAT-1 hybrid heterojunction was due to the possible electronic doping effect [36].

Before evaluating the enhancement of the photodetection performance of the $\mathrm{Bi}_{2} \mathrm{Se}_{3} / \mathrm{Ni}-\mathrm{CAT}-1$ hybrid heterojunction compared with that of the pristine $\mathrm{Bi}_{2} \mathrm{Se}_{3}$, the optical absorption properties of the device before and after Ni-CAT-1 nanoparticles hybridization were investigated in this study. According to Fig. $3 \mathrm{a}$, the pristine $\mathrm{Bi}_{2} \mathrm{Se}_{3}$ exhibited a certain light absorption capacity within the range of $500-1500 \mathrm{~nm}$. However its absorption in the range of $1500-2500 \mathrm{~nm}$ was weak, while the Ni-CAT-1 nanoparticles demonstrated a better absorption capacity than that of the pristine $\mathrm{Bi}_{2} \mathrm{Se}_{3}$ in the range of 500 $2500 \mathrm{~nm}$. When the Ni-CAT-1 nanoparticles were grown onto the $\mathrm{Bi}_{2} \mathrm{Se}_{3}$ channel, the $\mathrm{Bi}_{2} \mathrm{Se}_{3} / \mathrm{Ni}$-CAT-1 hybrid heterojunction exhibited enhanced absorption from 500 to $2500 \mathrm{~nm}$, which was ascribed to the synergetic absorption effect of Ni-CAT-1 nanoparticles and $\mathrm{Bi}_{2} \mathrm{Se}_{3}$ flake. Moreover, the $\mathrm{Bi}_{2} \mathrm{Se}_{3} / \mathrm{Ni}-\mathrm{CAT}-1$ hybrid heterojunction presented a strong absorption peak at around $1500 \mathrm{~nm}$, which was absent in the individual $2 \mathrm{D} \mathrm{Bi}_{2} \mathrm{Se}_{3}$ flake and Ni-CAT-1 nanoparticles. This phenomenon may be caused by the energy transfer between $\mathrm{Bi}_{2} \mathrm{Se}_{3}$ and Ni-CAT-1 [37]. The enhanced absorption and possible energy transfer enabled the $\mathrm{Bi}_{2} \mathrm{Se}_{3} / \mathrm{Ni}$-CAT-1 hybrid heterojunction as the high-performance broadband photodetector.

Then, we concentrated our efforts on the photoelectric performance of the $\mathrm{Bi}_{2} \mathrm{Se}_{3} / \mathrm{Ni}-\mathrm{CAT}-1$ hybrid heterojunction device. Fig. 3b, c show the photoelectric properties of the pristine $\mathrm{Bi}_{2} \mathrm{Se}_{3}$ and $\mathrm{Bi}_{2} \mathrm{Se}_{3} / \mathrm{Ni}$-CAT-1 hybrid heterojunction under illumination with various wavelengths ranging from 500 to $2000 \mathrm{~nm}$, respectively. Based on the curves in Fig. 3b, the pristine $2 \mathrm{D}$ $\mathrm{Bi}_{2} \mathrm{Se}_{3}$ flake exhibited an obvious photo-response in the spectral range of $500-1600 \mathrm{~nm}$, yet had a weak response in the nearinfrared region with the wavelength of $1000-1600 \mathrm{~nm}$ due to its weak light absorption. Under the same light irradiation condition, the $2 \mathrm{D} \mathrm{Bi}_{2} \mathrm{Se}_{3} / \mathrm{Ni}-\mathrm{CAT}-1$ hybrid heterojunction showed stronger photo-response than the pristine $2 \mathrm{D} \mathrm{Bi}_{2} \mathrm{Se}_{3}$ flake (Fig. 3c) because of its higher light absorption. In addition, on account of the broad spectral absorption of Ni-CAT-1 nanoparticles, the photo-response range of the $\mathrm{Bi}_{2} \mathrm{Se}_{3} / \mathrm{Ni}-\mathrm{CAT}-1$ hybrid heterojunction was extended to $2000 \mathrm{~nm}$, which was difficult to be achieved in a single $2 \mathrm{D} \mathrm{Bi}_{2} \mathrm{Se}_{3}$-based photodetector $[33,38]$. Fig. S4 displays the photo-response switching of the $\mathrm{Bi}_{2} \mathrm{Se}_{3} / \mathrm{Ni}-\mathrm{CAT}-1$ hybrid heterojunction under illumination at $500,1000,1500$, and $2000 \mathrm{~nm}$, respectively, indicating the highly reproducible and stable photo-response properties. These results further demonstrated that the Ni-CAT-1 nanoparticles hybridization not only enhanced the photodetection performance of the $2 \mathrm{D} \mathrm{Bi}_{2} \mathrm{Se}_{3}$ flake, but also broadened its photodetection range.

To better understand the performance improvement of the device based on the $2 \mathrm{D} \mathrm{Bi}_{2} \mathrm{Se}_{3}$ flake by Ni-CAT-1 nanoparticles hybridization, the photocurrent $\left(I_{\mathrm{ph}}\right)$, responsivity $(R)$, and detectivity $\left(D^{*}\right)$ of the pristine $\mathrm{Bi}_{2} \mathrm{Se}_{3}$ and $\mathrm{Bi}_{2} \mathrm{Se}_{3} / \mathrm{Ni}-\mathrm{CAT}-1$ hybrid heterojunction were systematically studied under different excitation wavelengths. $R$ and $D^{*}$ denote two important characteristic parameters to evaluate the performance of a photodetector, representing the ability of generating photocurrent under illumination and detecting minimum illumination signal, respectively. The calculation formula is expressed as follows [39]: $I_{\mathrm{ph}}=I_{\text {illuminated }}-I_{\text {dark }}, R=I_{\mathrm{ph}} /(P S), D^{*}=$ $R\left(S / 2 e I_{\text {dark }}\right)^{1 / 2}$, where the $I_{\text {illuminated }}, I_{\text {dark }}, P, S$, and $e$ refer to the device current under illumination, dark current, power density of incident light, device effective area, and elementary electronic 

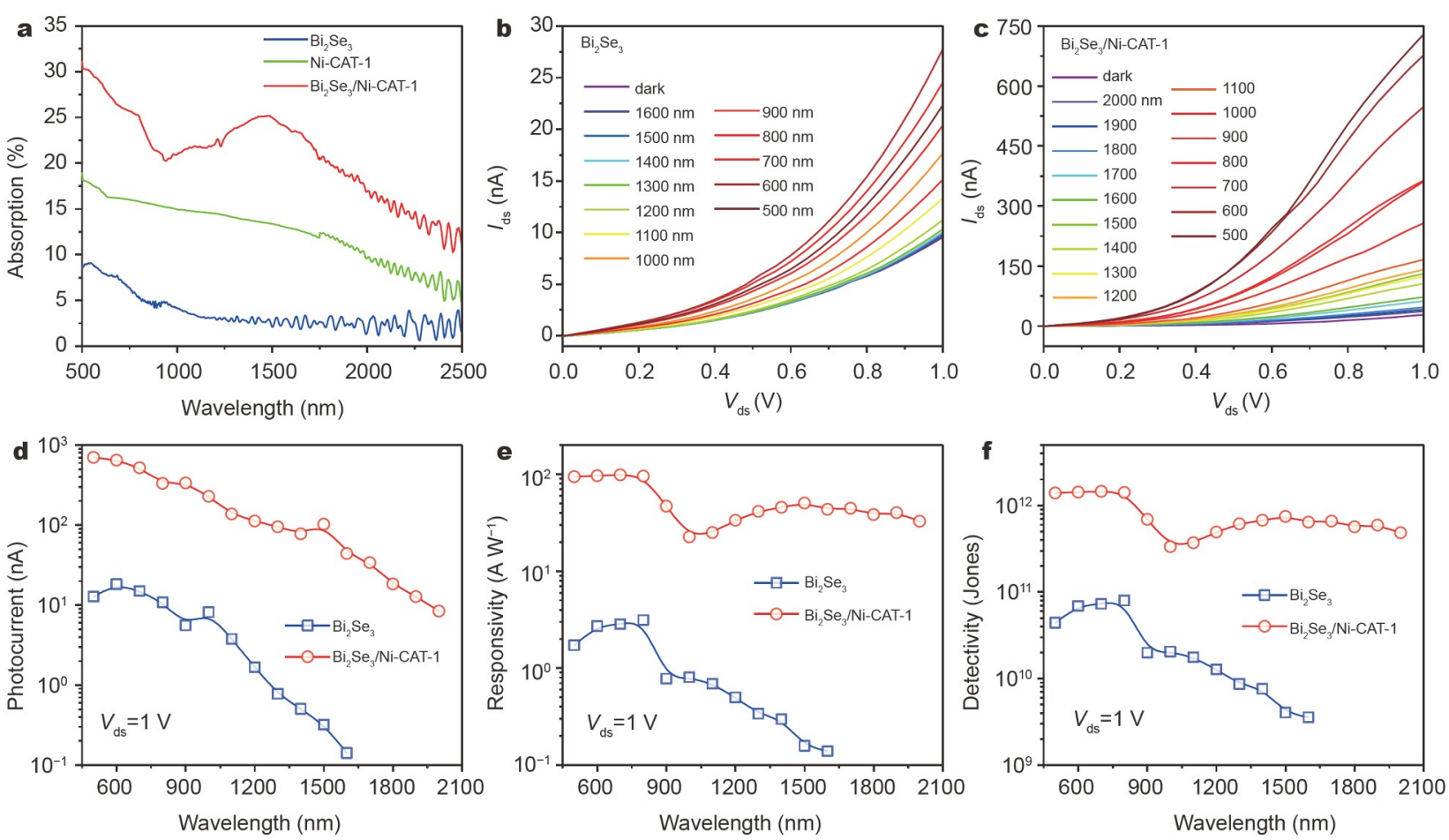

Figure 3 Broadband photodetection performance of the pristine $2 \mathrm{D} \mathrm{Bi}_{2} \mathrm{Se}_{3}$ flake and $2 \mathrm{D} \mathrm{Bi}_{2} \mathrm{Se}_{3} / \mathrm{Ni}-\mathrm{CAT}-1$ hybrid heterojunction. (a) Optical absorption spectra of the pristine $\mathrm{Bi}_{2} \mathrm{Se}_{3}, \mathrm{Ni}-\mathrm{CAT}-1$ nanoparticles and $\mathrm{Bi}_{2} \mathrm{Se}_{3} / \mathrm{Ni}-\mathrm{CAT}-1$ hybrid heterojunction. (b) $I_{\mathrm{ds}}-V_{\mathrm{ds}}$ curves of the pristine Bi $\mathrm{Se}_{3}$ device in the dark and under illumination with various wavelengths ranging from 500 to $1600 \mathrm{~nm}$. (c) $I_{\mathrm{ds}^{-}}-V_{\mathrm{ds}}$ curves of the Bi $\mathrm{Se}_{3} / \mathrm{Ni}_{-}-\mathrm{CAT}-1$ hybrid heterojunction in the dark and under illumination with various wavelengths ranging from 500 to $2000 \mathrm{~nm}$. (d) Photocurrent, (e) responsivity and (f) detectivity of the Bi $\mathrm{Se}_{3}$ devices with and without Ni-CAT-1 nanoparticles hybridization at wavelengths from 500 to $2000 \mathrm{~nm}$, respectively.

charge, respectively. Fig. $3 \mathrm{~d}$ shows the $I_{\mathrm{ph}}$ actually obtained from Fig. 3b, $c$ under different wavelengths, while Fig. $3 e, f$ present the calculated $R$ and $D^{*}$ based on Fig. 3 d. Clearly, the photocurrent of the $\mathrm{Bi}_{2} \mathrm{Se}_{3} / \mathrm{Ni}$-CAT-1 hybrid heterojunction under excitation at different wavelengths was 2-3 orders of magnitude higher than that of the pristine $\mathrm{Bi}_{2} \mathrm{Se}_{3}$, indicating that hybridization is an extremely effective strategy to improve the photodetection performance of the $2 \mathrm{D} \mathrm{Bi}_{2} \mathrm{Se}_{3}$ flake. Regarding the $\mathrm{Bi}_{2} \mathrm{Se}_{3} / \mathrm{Ni}$ CAT-1 hybrid heterojunction, the $R$ values were calculated to be $94.5,22.6,50.5$, and $32.8 \mathrm{~A} \mathrm{~W}^{-1}$ at 500, 1000, 1500, and $2000 \mathrm{~nm}$, respectively. Comparatively, the pristine $2 \mathrm{D} \mathrm{Bi}_{2} \mathrm{Se}_{3}$ flake exhibited much smaller $R$ values of $1.7,0.8$, and $0.14 \mathrm{~A} \mathrm{~W}^{-1}$ at 500 , 1000 , and $1500 \mathrm{~nm}$, respectively. Similarly, the $D^{*}$ of the $\mathrm{Bi}_{2} \mathrm{Se}_{3} /$ Ni-CAT-1 hybrid heterojunction reached up to $1.4 \times 10^{12}, 3.3 \times$ $10^{11}, 7.5 \times 10^{11}$, and $4.8 \times 10^{11}$ Jones at 500,1000,1500, and $2000 \mathrm{~nm}$, respectively, which were much higher than that of the pristine $2 \mathrm{D} \mathrm{Bi}_{2} \mathrm{Se}_{3}$ flake $\left(4.4 \times 10^{10}\right.$ Jones at $500 \mathrm{~nm}, 2.1 \times 10^{10}$ Jones at $1000 \mathrm{~nm}$ and $4.1 \times 10^{9}$ Jones at $\left.1500 \mathrm{~nm}\right)$. In addition, the EQE values of the pristine $2 \mathrm{D} \mathrm{Bi}_{2} \mathrm{Se}_{3}$ flake and $\mathrm{Bi}_{2} \mathrm{Se}_{3} / \mathrm{Ni}$ CAT-1 hybrid heterojunction were estimated by the following formula: $\mathrm{EQE}=h c R / e \lambda$, where $h, c, e, \lambda$ and $R$ refer to the Planck constant, light velocity, elementary electronic charge, incident wavelength and responsivity, respectively. The as-estimated EQE values of the $\mathrm{Bi}_{2} \mathrm{Se}_{3} / \mathrm{Ni}-\mathrm{CAT}-1$ hybrid heterojunction were $23,495 \%, 2809 \%$ and $4185 \%$ at 500, 1000 and $1500 \mathrm{~nm}$, higher than that of the pristine $2 \mathrm{D} \mathrm{Bi}_{2} \mathrm{Se}_{3}$ flake $(423 \% / 99 \% / 11 \%$ at $500 /$ $1000 / 1500 \mathrm{~nm})$. Briefly, the $\mathrm{Bi}_{2} \mathrm{Se}_{3} / \mathrm{Ni}-\mathrm{CAT}-1$ hybrid heterojunction photodetector demonstrated an overall improvement in the aspect of photocurrent, responsivity, detectivity and EQE compared with the pristine $\mathrm{Bi}_{2} \mathrm{Se}_{3}$.
From the above analyses, the $\mathrm{Bi}_{2} \mathrm{Se}_{3} / \mathrm{Ni}-\mathrm{CAT}-1$ hybrid heterojunction exhibited a superior photodetection performance at $1500 \mathrm{~nm}$ compared with the pristine $\mathrm{Bi}_{2} \mathrm{Se}_{3}$. Thus, the excitation wavelength used in the following studies was set to $1500 \mathrm{~nm}$. Fig. 4 a displays the output characteristic curves of the $\mathrm{Bi}_{2} \mathrm{Se}_{3} / \mathrm{Ni}$ CAT-1 hybrid heterojunction under $1500 \mathrm{~nm}$ illumination with various power densities (from 0.012 to $1.012 \mathrm{~mW} \mathrm{~cm}^{-2}$ ). The drain current monotonically increased with the increasing power density. The photocurrent as a function of power density at $V_{\mathrm{ds}}=1 \mathrm{~V}$ was plotted in Fig. $4 \mathrm{~b}$, which was fitted in a simple power law $I_{\mathrm{ph}} \sim P^{\alpha}$. The $\alpha$ is a constant related to the generation, trapping and recombination of photo-generated carriers. The fitted $\alpha$ is 0.38 , indicating the presence of trap-assisted photogenerated electron-hole pairs recombination at the interface of the $\mathrm{Bi}_{2} \mathrm{Se}_{3} / \mathrm{Ni}-\mathrm{CAT}-1$ hybrid heterojunction [40,41]. Additionally, the responsivity as a function of power density was plotted in Fig. 4c. The obtained maximum responsivity was calculated to be $395 \mathrm{~A} \mathrm{~W}^{-1}$ at a low incident power density of $0.012 \mathrm{~mW} \mathrm{~cm}^{-2}$. Moreover, the photo-response switching of the $\mathrm{Bi}_{2} \mathrm{Se}_{3} / \mathrm{Ni}-\mathrm{CAT}-1$ hybrid heterojunction exhibited good stability, which was found in Fig. S5. Through careful analysis of one of the cycles, it was found that the $\mathrm{Bi}_{2} \mathrm{Se}_{3} / \mathrm{Ni}-\mathrm{CAT}-1$ hybrid heterojunction exhibited a fast photo-response rate. According to Fig. $4 \mathrm{~d}$, the rising time $\left(\tau_{\text {rising }}\right)$ and decay time $\left(\tau_{\text {decay }}\right)$ of the heterojunction were $\sim 130$ and $\sim 6 \mathrm{~ms}$, respectively, faster than those of the individual $\mathrm{Bi}_{2} \mathrm{Se}_{3}$ device ( $\tau_{\text {rising }} \sim 0.54 \mathrm{~s}, \tau_{\text {decay }} \sim 0.47 \mathrm{~s}$ ) [33]. The fast photo-response rate in the $\mathrm{Bi}_{2} \mathrm{Se}_{3} / \mathrm{Ni}$-CAT-1 hybrid heterojunction was possibly attributed to the Schottky contact at the electrode $/ \mathrm{Bi}_{2} \mathrm{Se}_{3}$ interface, as inferred from the non-linear $I_{\mathrm{ds}}-V_{\mathrm{ds}}$ curves. The Schottky barrier efficiently promoted the separation of photo-generated 

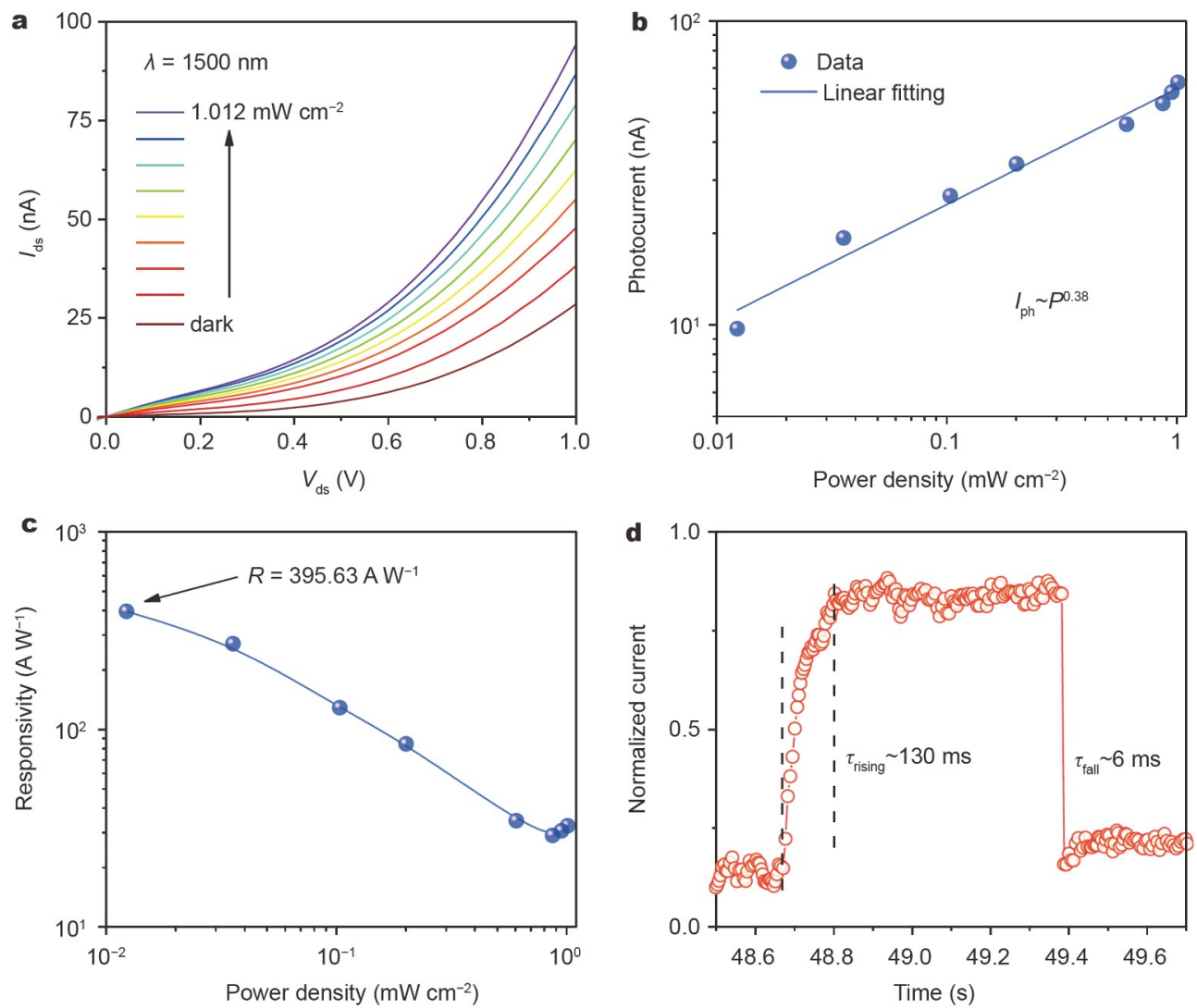

Figure 4 Photoresponse properties of the $\mathrm{Bi}_{2} \mathrm{Se}_{3} / \mathrm{Ni}-\mathrm{CAT}-1$ hybrid heterojunction under $1500 \mathrm{~nm}$ illumination. (a) $I_{\mathrm{ds}^{-}}-V_{\mathrm{ds}}$ curves of the Bi $\mathrm{Se}_{3} / \mathrm{Ni}_{\mathrm{i}}-\mathrm{CAT}-1$ hybrid heterojunction in the dark and under illumination with various power densities ranging from 0.012 to $1.012 \mathrm{~mW} \mathrm{~cm}{ }^{-2}$. (b, c) Light-power-dependent photocurrent and responsivity at $V_{\mathrm{ds}}=1 \mathrm{~V}$. (d) Response rate of the $\mathrm{Bi}_{2} \mathrm{Se}_{3} / \mathrm{Ni}-\mathrm{CAT}-1$ hybrid heterojunction with a rising time of $130 \mathrm{~ms}$ and a decay time of $6 \mathrm{~ms}$.

electron-hole pairs, leading to a fast photo-response dynamics $[14,42]$.

To explore the possible photo-response mechanism in the $\mathrm{Bi}_{2} \mathrm{Se}_{3} / \mathrm{Ni}$-CAT-1 hybrid heterojunction, the gate-modulated photo-response was further investigated in detail. The transfer characteristic curves of the $\mathrm{Bi}_{2} \mathrm{Se}_{3} / \mathrm{Ni}$-CAT- 1 hybrid heterojunction in dark and under $1500 \mathrm{~nm}$ illumination with various power densities are illustrated in Fig. 5a. The drain current of the heterojunction increased with the increasing power density in the gate voltage range of $-60-60 \mathrm{~V}$. In addition, the $\mathrm{Bi}_{2} \mathrm{Se}_{3} / \mathrm{Ni}$ CAT-1 hybrid heterojunction presented a stable and repeatable photo-response under $1500 \mathrm{~nm}$ illumination with a power density of $1.012 \mathrm{~mW} \mathrm{~cm}^{-2}$ at $V_{\mathrm{ds}}=1 \mathrm{~V}$ and $V_{\mathrm{gs}}=0 \mathrm{~V}$ (Fig. 5b). Fig. 5c depicts the power density dependence of photocurrent at different gate voltages, which were fitted by the power law of $I_{\mathrm{ph}} \sim$ $P^{\alpha}$. Regarding a photodetector, the $\alpha$ value is related to the two photo-response mechanisms of photogating effect $(\alpha<1)$ and photoconductive effect $(\alpha \approx 1)$ [43,44]. The $\alpha$ values of the $\mathrm{Bi}_{2} \mathrm{Se}_{3} / \mathrm{Ni}$-CAT-1 hybrid heterojunction at different gate voltages are displayed in Fig. 5d. Therefore, it was found that the obtained $\alpha$ value varied from 0.26 to 0.41 in the gate voltage range from -60 to $60 \mathrm{~V}$, much smaller than 1 , manifesting that the photogating effect was the dominating photo-response mechanism. Under the photogating effect, the photo-generated electrons in the $\mathrm{Bi}_{2} \mathrm{Se}_{3} / \mathrm{Ni}$-CAT-1 hybrid heterojunction circulated multiple times in the channel due to the modulation of the charged trap states, resulting in a high photoconductive gain $(G)$.
[45,46] The $G$ can be estimated by the equation [39]: $G=\tau_{\text {life }} /$ $\tau_{\text {tran }}$, where the $\tau_{\text {life }}$ and $\tau_{\text {tran }}$ are the lifetime of photo-generated carriers and the drift transit time of carriers, respectively. The lifetime $\left(\tau_{\text {life }}\right)$ could be presented by the response time $(\sim 6 \mathrm{~ms})$ and the transit time $\left(\tau_{\text {tran }}\right)$ was written as [39]: $\tau_{\text {tran }}=L^{2} /\left(\mu V_{\text {bias }}\right)$, where $L, \mu$ and $V_{\text {bias }}$ refer to the channel length, carrier mobility and bias voltage, respectively. The calculated $G$ reached up to 6.3 $\times 10^{4}$, indicating that high photodetection performance was obtained in the $\mathrm{Bi}_{2} \mathrm{Se}_{3} / \mathrm{Ni}-\mathrm{CAT}-1$ hybrid heterojunction.

Fig. 5e, $\mathrm{f}$ demonstrate gate-modulated responsivity and detectivity of the $\mathrm{Bi}_{2} \mathrm{Se}_{3} / \mathrm{Ni}-\mathrm{CAT}-1$ hybrid heterojunction, which increased sharply with the increase of the applied gate voltage. The behavior was explained by a gate-modulated energy band structure $[17,36]$. Under the equilibrium conditions of no illumination and gate voltage, the photoelectrical properties were mainly affected by the Schottky barrier at the contact interface (Fig. 5g). The Schottky barrier significantly increased at the negative gate voltage, leading to negligible thermionic and tunneling current. As a result, the channel current was contributed by the photo-generated carriers of $\mathrm{Bi}_{2} \mathrm{Se}_{3}$ and Ni-CAT-1 under illumination (Fig. 5h). Under positive gate voltage, in addition to the photo-generated current, the thermionic and tunneling current gradually increased as a result of decreasing Schottky barrier height, thus forming a significantly increased channel current (Fig. 5i). Therefore, on account of the synergistic effect of tunable Schottky barrier and photogating mechanism, the channel current remarkably increased at the positive gate vol- 

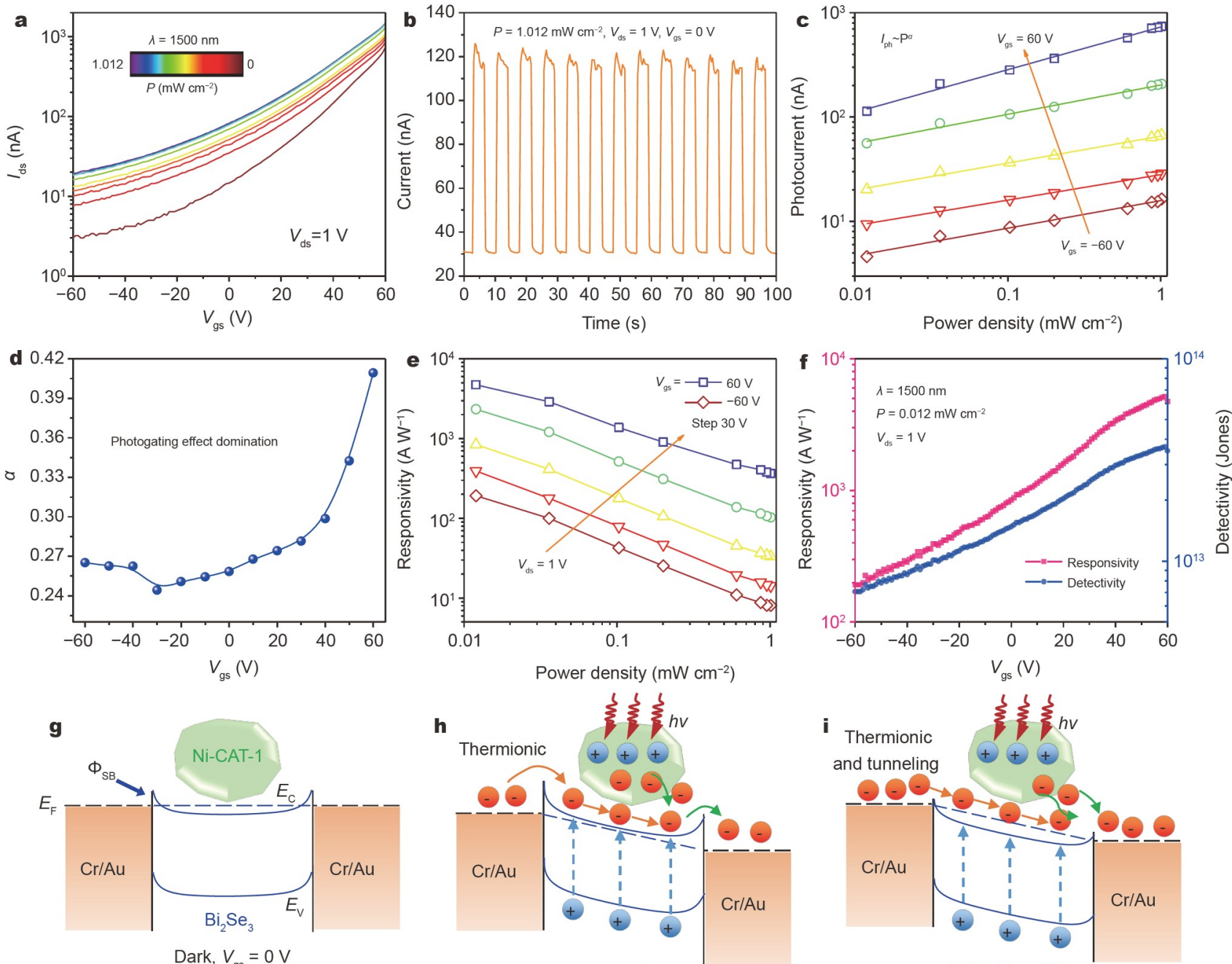

Light, $V_{\mathrm{gs}}<0 \mathrm{~V}$

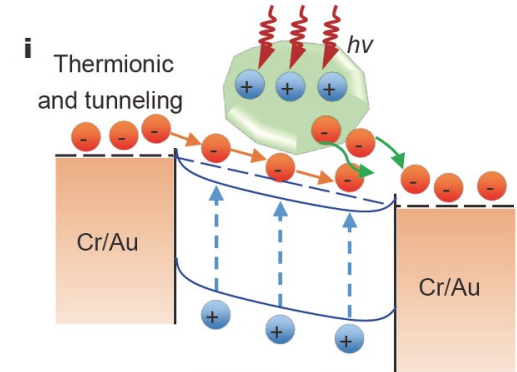

Light, $V_{\mathrm{gs}}>0 \mathrm{~V}$

Figure 5 Gate-modulated photodetection performance of the $\mathrm{Bi}_{2} \mathrm{Se}_{3} / \mathrm{Ni}$-CAT-1 hybrid heterojunction under illumination at $1500 \mathrm{~nm}$. (a) Transfer characteristic curves of the $\mathrm{Bi}_{2} \mathrm{Se}_{3} / \mathrm{Ni}$-CAT-1 hybrid heterojunction in the dark and under $1500 \mathrm{~nm}$ illumination with various power densities ranging from 0.012 to $1.012 \mathrm{~mW} \mathrm{~cm}^{-2}$. (b) Time-resolved photoresponse at a power density of $1.012 \mathrm{~mW} \mathrm{~cm}^{-2}, V_{\mathrm{ds}}=1 \mathrm{~V}$ and $V_{\mathrm{gs}}=0 \mathrm{~V}$. (c) Power-dependent photocurrent at different gate voltages. (d) Exponent $(\alpha)$ extracted from (c) for each gate voltage. (e) Light-power-dependent responsivity at different gate voltages. (f) Responsivity and detectivity as a function of gate voltage. The carrier transport mechanism and band energy diagram of the $\mathrm{Bi}_{2} \mathrm{Se}_{3} / \mathrm{Ni}-\mathrm{CAT}-1 \mathrm{hybrid}$ heterojunction at (g) equilibrium state, (h) $V_{\mathrm{gs}}<0 \mathrm{~V}$, and (i) $V_{\mathrm{gs}}>0 \mathrm{~V}$.

Table 1 Comparison of photodetection performance between the $\mathrm{Bi}_{2} \mathrm{Se}_{3} / \mathrm{Ni}$-CAT hybrid heterojunction and other photodetectors with similar structure

\begin{tabular}{|c|c|c|c|c|c|c|}
\hline Device & Wavelength (nm) & $\begin{array}{l}\text { Bias } \\
(V)\end{array}$ & Responsivity $\left(\mathrm{A} \mathrm{W}^{-1}\right)$ & Detectivity (Jones) & Response rate & Ref. \\
\hline $\mathrm{Bi}_{2} \mathrm{Se}_{3} / \mathrm{Ni}-\mathrm{CAT}-1$ & 1500 & $\begin{array}{c}V_{\mathrm{ds}}=1 \\
V_{\mathrm{gs}}=60\end{array}$ & 4725 & $3.5 \times 10^{13}$ & $130 / 6 \mathrm{~ms}$ & This work \\
\hline $\mathrm{Bi}_{2} \mathrm{Se}_{3} / \mathrm{MoO}_{3}$ & 1550 & $V_{\mathrm{ds}}=20$ & 739 & $\sim 3 \times 10^{10}$ & $62 / 76 \mu \mathrm{s}$ & [2] \\
\hline $\mathrm{Bi}_{2} \mathrm{Te}_{3} /$ pentacene & 1550 & $V_{\mathrm{ds}}=0$ & $\sim 1$ & $\sim 10^{9}$ & $3.26 / 5.07 \mathrm{~ms}$ & {$[47]$} \\
\hline Graphene/HgTe & 2500 & $\begin{array}{c}V_{\mathrm{ds}}=1 \\
V_{\mathrm{gs}}=-2.5\end{array}$ & $6.5 \times 10^{-3}$ & $\sim 10^{9}$ & $10^{-5} \mathrm{~s}$ & {$[48]$} \\
\hline $\mathrm{MoS}_{2} / \mathrm{PbS}$ & 1200 & $V_{\mathrm{ds}}=2$ & 0.543 & $2.68 \times 10^{12}$ & - & [49] \\
\hline $\mathrm{MoS}_{2} / \mathrm{CuInSe} e_{2}$ & 1064 & $\begin{array}{c}V_{\mathrm{ds}}=1 \\
V_{\mathrm{gs}}=60\end{array}$ & 74.8 & $7.1 \times 10^{11}$ & $1.5 / 1.2 \mathrm{~s}$ & {$[36]$} \\
\hline Ge/Perovskite & 980 & $V_{\mathrm{ds}}=1$ & 32 & $2.2 \times 10^{9}$ & $2.1 / 5.7 \mathrm{~ms}$ & {$[50]$} \\
\hline
\end{tabular}

tage, causing the high photodetection performance. Obviously, the $\mathrm{Bi}_{2} \mathrm{Se}_{3} / \mathrm{Ni}$-CAT-1 hybrid heterojunction reached a respon- sivity of $4725 \mathrm{~A} \mathrm{~W}^{-1}$ and a detectivity of $3.5 \times 10^{13}$ Jones at $V_{\mathrm{gs}}=$ $60 \mathrm{~V}$. Based on Table 1, the present device performance of 
$\mathrm{Bi}_{2} \mathrm{Se}_{3} / \mathrm{Ni}-\mathrm{CAT}-1$ is superior to that of the reported photodetectors with similar structure.

\section{CONCLUSIONS}

To conclude, a high-performance infrared photodetector based on $2 \mathrm{D} \mathrm{Bi}_{2} \mathrm{Se}_{3}$ flakes was fabricated with the hybridization of MOF (Ni-CAT-1) nanoparticles through a simple solution process. Benefiting from the strong optical absorption of MOF (Ni-CAT-1) nanoparticles and the high carrier mobility of 2D $\mathrm{Bi}_{2} \mathrm{Se}_{3}$ flake, the $\mathrm{Bi}_{2} \mathrm{Se}_{3} / \mathrm{MOF}$ hybrid heterojunction demonstrated excellent photo-response performance in the wavelength range of $500-2000 \mathrm{~nm}$, with 2-3 orders of magnitude higher than that of the pristine $\mathrm{Bi}_{2} \mathrm{Se}_{3}$-based photodetector. Specifically, an outstanding responsivity of $4725 \mathrm{~A} \mathrm{~W}^{-1}$ and a high detectivity of $3.5 \times 10^{13}$ Jones were achieved at $1500 \mathrm{~nm}$ due to the synergistic effect of photogating effect and the gate-modulated Schottky barrier. These results demonstrated the potential of MOF nanomaterials in enhancing the photodetection performance of photodetectors based on 2D layered materials.

\section{Received 26 July 2021; accepted 27 August 2021;}

published online 29 September 2021

1 Guan X, Yu X, Periyanagounder D, et al. Recent progress in short- to long-wave infrared photodetection using $2 \mathrm{D}$ materials and heterostructures. Adv Opt Mater, 2020, 9: 2001708

2 Yang M, Han Q, Liu X, et al. Ultrahigh stability 3D TI $\mathrm{Bi}_{2} \mathrm{Se}_{3} / \mathrm{MoO}_{3}$ thin film heterojunction infrared photodetector at optical communication waveband. Adv Funct Mater, 2020, 30: 1909659

3 Tan C, Amani M, Zhao C, et al. Evaporated $\mathrm{Se}_{x} \mathrm{Te}_{1-x}$ thin films with tunable bandgaps for short-wave infrared photodetectors. Adv Mater, 2020, 32: 2001329

4 Wang P, Xia H, Li Q, et al. Sensing infrared photons at room temperature: From bulk materials to atomic layers. Small, 2019, 15: 1904396

5 Wang F, Zhang Y, Gao Y, et al. 2D metal chalcogenides for IR photodetection. Small, 2019, 15: 1901347

6 Tong L, Peng M, Wu P, et al. Hole-dominated Fowler-Nordheim tunneling in 2D heterojunctions for infrared imaging. Sci Bull, 2021, 66: $139-146$

7 Liu J, Xia F, Xiao D, et al. Semimetals for high-performance photodetection. Nat Mater, 2020, 19: 830-837

8 Wang F, Pei K, Li Y, et al. 2D homojunctions for electronics and optoelectronics. Adv Mater, 2021, 33: 2005303

9 Liu R, Wang F, Liu L, et al. Band alignment engineering in two-dimensional transition metal dichalcogenide-based heterostructures for photodetectors. Small Struct, 2020, 2: 2000136

10 Liu L, Zhai T. Wafer-scale vertical van der Waals heterostructures. InfoMat, 2020, 3: 3-21

11 Guo Z, Cao R, Wang H, et al. High performance polarization sensitive photodetectors on two-dimensional $\beta$-InSe. Natl Sci Rev, 2021, doi: 10.1093/nsr/nwab098

12 Konstantatos G, Badioli M, Gaudreau L, et al. Hybrid graphenequantum dot phototransistors with ultrahigh gain. Nat Nanotech, 2012, 7: $363-368$

13 Chen Z, Li X, Wang J, et al. Synergistic effects of plasmonics and electron trapping in graphene short-wave infrared photodetectors with ultrahigh responsivity. ACS Nano, 2017, 11: 430-437

14 Dai M, Chen H, Feng R, et al. A dual-band multilayer InSe self-powered photodetector with high performance induced by surface plasmon resonance and asymmetric Schottky junction. ACS Nano, 2018, 12: 8739-8747

15 Huo N, Gupta S, Konstantatos G. $\mathrm{MoS}_{2}-\mathrm{HgTe}$ quantum dot hybrid photodetectors beyond $2 \mu \mathrm{m}$. Adv Mater, 2017, 29: 1606576

16 Luo $\mathrm{P}$, Zhuge F, Wang F, et al. PbSe quantum dots sensitized highmobility $\mathrm{Bi}_{2} \mathrm{O}_{2} \mathrm{Se}$ nanosheets for high-performance and broadband photodetection beyond $2 \mu \mathrm{m}$. ACS Nano, 2019, 13: 9028-9037

$17 \mathrm{Wu} \mathrm{H}, \mathrm{Si} \mathrm{H}$, Zhang Z, et al. All-inorganic perovskite quantum dotmonolayer $\mathrm{MoS}_{2}$ mixed-dimensional van der Waals heterostructure for ultrasensitive photodetector. Adv Sci, 2018, 5: 1801219

18 Wang L, Zou X, Lin J, et al. Perovskite/black phosphorus/MoS 2 photogate reversed photodiodes with ultrahigh light on/off ratio and fast response. ACS Nano, 2019, 13: 4804-4813

19 Yang T, Wang X, Zheng B, et al. Ultrahigh-performance optoelectronics demonstrated in ultrathin perovskite-based vertical semiconductor heterostructures. ACS Nano, 2019, 13: 7996-8003

20 Yu X, Li Y, Hu X, et al. Narrow bandgap oxide nanoparticles coupled with graphene for high performance mid-infrared photodetection. Nat Commun, 2018, 9: 4299

21 Zhou N, Xu B, Gan L, et al. Narrowband spectrally selective nearinfrared photodetector based on up-conversion nanoparticles used in a 2D hybrid device. J Mater Chem C, 2017, 5: 1591-1595

22 Dong $\mathrm{R}$, Han $\mathrm{P}$, Arora $\mathrm{H}$, et al. High-mobility band-like charge transport in a semiconducting two-dimensional metal-organic framework. Nat Mater, 2018, 17: 1027-1032

23 Bera KP, Haider G, Usman M, et al. Trapped photons induced ultrahigh external quantum efficiency and photoresponsivity in hybrid graphene/metal-organic framework broadband wearable photodetectors. Adv Funct Mater, 2018, 28: 1804802

24 Arora H, Dong R, Venanzi T, et al. Demonstration of a broadband photodetector based on a two-dimensional metal-organic framework. Adv Mater, 2020, 32: 1907063

25 Liang B, Lin RB, Chen B. Emerging 2D functional metal-organic framework materials. Natl Sci Rev, 2020, 7: 3-5

26 Ma Y, Lu Y, Hai G, et al. Bidentate carboxylate linked $\mathrm{TiO}_{2}$ with $\mathrm{NH}_{2}-$ MIL-101(Fe) photocatalyst: A conjugation effect platform for high photocatalytic activity under visible light irradiation. Sci Bull, 2020, 65: 658-669

27 Wang L, Jin P, Duan S, et al. In-situ incorporation of copper(II) porphyrin functionalized zirconium $\mathrm{MOF}$ and $\mathrm{TiO}_{2}$ for efficient photocatalytic $\mathrm{CO}_{2}$ reduction. Sci Bull, 2019, 64: 926-933

28 Yan ZH, Ma B, Li SR, et al. Encapsulating a Ni(II) molecular catalyst in photoactive metal-organic framework for highly efficient photoreduction of $\mathrm{CO}_{2}$. Sci Bull, 2019, 64: 976-985

$29 \mathrm{Wu}$ J, Chen J, Wang C, et al. Metal-organic framework for transparent electronics. Adv Sci, 2020, 7: 1903003

30 Allendorf $\mathrm{MD}$, Dong R, Feng $\mathrm{X}$, et al. Electronic devices using open framework materials. Chem Rev, 2020, 120: 8581-8640

31 Wang F, Luo $\mathrm{P}$, Zhang $\mathrm{Y}$, et al. Band structure engineered tunneling heterostructures for high-performance visible and near-infrared photodetection. Sci China Mater, 2020, 63: 1537-1547

32 Zhang J, Peng Z, Soni A, et al. Raman spectroscopy of few-quintuple layer topological insulator $\mathrm{Bi}_{2} \mathrm{Se}_{3}$ nanoplatelets. Nano Lett, 2011, 11: 2407-2414

33 Wang F, Li L, Huang W, et al. Submillimeter $2 \mathrm{D} \mathrm{Bi}_{2} \mathrm{Se}_{3}$ flakes toward high-performance infrared photodetection at optical communication wavelength. Adv Funct Mater, 2018, 28: 1802707

34 Shao F, Dai W, Zhang Y, et al. Chemical mapping of nanodefects within $2 \mathrm{D}$ covalent monolayers by tip-enhanced Raman spectroscopy. ACS Nano, 2018, 12: 5021-5029

35 Sun X, Zhu C, Liu H, et al. Contact and injection engineering for low SS reconfigurable FETs and high gain complementary inverters. Sci Bull, 2020, 65: 2007-2013

36 Shen $\mathrm{T}$, Li F, Zhang $\mathrm{Z}$, et al. High-performance broadband photodetector based on monolayer $\mathrm{MoS}_{2}$ hybridized with environmentfriendly CuInSe $e_{2}$ quantum dots. ACS Appl Mater Interfaces, 2020, 12: 54927-54935

37 Iqbal MA, Liaqat A, Hussain S, et al. Ultralow-transition-energy organic complex on graphene for high-performance shortwave infrared photodetection. Adv Mater, 2020, 32: 2002628

38 Liu JL, Chen H, Li X, et al. Ultra-fast and high flexibility near-infrared photodetectors based on $\mathrm{Bi}_{2} \mathrm{Se}_{3}$ nanobelts grown via catalyst-free van der Waals epitaxy. J Alloys Compd, 2020, 818: 152819

39 Long $\mathrm{M}$, Wang $\mathrm{P}$, Fang $\mathrm{H}$, et al. Progress, challenges, and opportunities for 2D material based photodetectors. Adv Funct Mater, 2019, 29: 


\section{7}

40 Hu C, Dong D, Yang X, et al. Synergistic effect of hybrid PbS quantum dots/2D-WSe $\mathrm{D}_{2}$ toward high performance and broadband phototransistors. Adv Funct Mater, 2017, 27: 1603605

41 Zhang Y, Wang J, Wang B, et al. Extending the spectral responsivity of $\mathrm{MoS}_{2}$ phototransistors by incorporating up-conversion microcrystals. Adv Opt Mater, 2018, 6: 1800660

42 Dai $\mathrm{M}$, Chen $\mathrm{H}$, Wang $\mathrm{F}$, et al. Ultrafast and sensitive self-powered photodetector featuring self-limited depletion region and fully depleted channel with van der Waals contacts. ACS Nano, 2020, 14: 9098-9106

43 Wang $\mathrm{F}$, Zhang $\mathrm{Z}$, Zhang $\mathrm{Y}$, et al. Honeycomb $\mathrm{RhI}_{3}$ flakes with high environmental stability for optoelectronics. Adv Mater, 2020, 32: 2001979

44 Island JO, Blanter SI, Buscema M, et al. Gate controlled photocurrent generation mechanisms in high-gain $\mathrm{In}_{2} \mathrm{Se}_{3}$ phototransistors. Nano Lett, 2015, 15: 7853-7858

45 Li L, Wang W, Chai Y, et al. Few-layered $\mathrm{PtS}_{2}$ phototransistor on h-BN with high gain. Adv Funct Mater, 2017, 27: 1701011

46 Zhang YJ, Ye JT, Yomogida Y, et al. Formation of a stable p-n junction in a liquid-gated $\mathrm{MoS}_{2}$ ambipolar transistor. Nano Lett, 2013, 13: 30233028

47 Yang $\mathrm{M}$, Wang J, Zhao Y, et al. Three-dimensional topological insulator $\mathrm{Bi}_{2} \mathrm{Te}_{3}$ /organic thin film heterojunction photodetector with fast and wideband response from 450 to 3500 nanometers. ACS Nano, 2019, 13: 755-763

48 Noumbé UN, Gréboval C, Livache C, et al. Reconfigurable 2D/0D p-n graphene/HgTe nanocrystal heterostructure for infrared detection. ACS Nano, 2020, 14: 4567-4576

49 Mukherjee S, Jana S, Sinha TK, et al. Infrared tunable, two colour-band photodetectors on flexible platforms using 0D/2D PbS-MoS 2 hybrids. Nanoscale Adv, 2019, 1: 3279-3287

$50 \mathrm{Hu} \mathrm{W}$, Cong $\mathrm{H}$, Huang $\mathrm{W}$, et al. Germanium/perovskite heterostructure for high-performance and broadband photodetector from visible to infrared telecommunication band. Light Sci Appl, 2019, 8: 106

Acknowledgements This work was supported by the National Natural Science Foundation of China (21825103 and 51727809), the Natural Science Foundation of Hubei Province (2019CFA002), the Fundamental Research Funds for the Central Universities (2019kfyXMBZ018) and China Postdoctoral Science Foundation (2021M691108). The authors thank the Analytical and Testing Centre of Huazhong University of Science and Technology.

Author contributions Wang $\mathrm{F}$ and Zhang $\mathrm{N}$ performed the growth of 2D $\mathrm{Bi}_{2} \mathrm{Se}_{3}$ flakes. Wang $\mathrm{F}$ and $\mathrm{Wu} \mathrm{J}$ fabricated the $\mathrm{Bi}_{2} \mathrm{Se}_{3} / \mathrm{Ni}$-CAT- 1 hybrid heterojunctions. Zhang Y did the AFM measurement. Wang F performed the properties characterization, device tests and manuscript writing. Zhai T supervised the project. Wang F, Yang $\mathrm{S}, \mathrm{Li} \mathrm{H}$ and Zhai $\mathrm{T}$ discussed the manuscript and revision.

Conflict of interest The authors declare that they have no conflict of interest.

Supplementary information version of the paper.

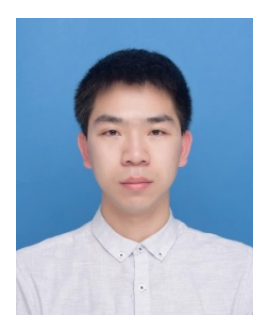

Fakun Wang received his BSc degree in mineral processing engineering from the Central South University in 2016. He is studying for his $\mathrm{PhD}$ degree at Huazhong University and Technology (HUST) under the supervision of Professor Tianyou Zhai. His work focuses on the controllable synthesis of low-dimensional inorganic materials, and their promising applications in optoelectronics.

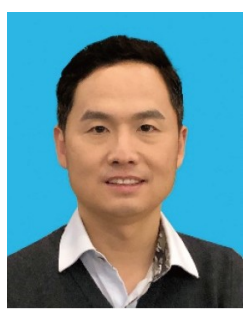

Tianyou Zhai received his BSc degree in chemistry from Zhengzhou University in 2003, and $\mathrm{PhD}$ degree in physical chemistry from the Institute of Chemistry, Chinese Academy of Sciences (ICCAS) under the supervision of Prof. Jiannian Yao in 2008. Afterwards he joined in the National Institute for Materials Science (NIMS) as a postdoctoral fellow of Japan Society for the Promotion of Science (JSPS) in Prof. Yoshio Bando's group and then as a researcher of the International Center for Young Scientists (ICYS) within NIMS. Currently, he is a chief professor of the School of Materials Science and Engineering, HUST. His research interests include the controlled synthesis and exploration of fundamental physical properties of inorganic functional nanomaterials, as well as their promising applications in energy science, electronics and optoelectronics.

\section{金属有机框架集成二维层状材料用于高性能短波红 外光探测}

王发坤, 吴洁, 张悦, 杨思捷, 张娜, 李会巧, 翟天佑 ${ }^{*}$

摘要 工作在短波红外区域的光电探测器因其在商业和军事领域的广 泛应用而备受重视，窄带隙二维层状材料(2DLM)被认为是构筑下一代 高性能红外光电探测器的潜在候选者. 然而, 这类材料在原子级厚度时 光吸收较弱, 致使其探测性能难以满足实际需求. 在本文中, 我们提出 了一种通过集成具有优异光吸收特性的金属有机骨架(MOF)纳米粒子 和高迁移率的2DLM来设计高性能短波红外光电探测器的策略, 并通过 构筑MOF/2DLM(Ni-CAT-1/ $\mathrm{Bi}_{2} \mathrm{Se}_{3}$ ) 混合异质结光电探测器演示了该策 略的可行性. 由于光生载流子从MOF转移到 $\mathrm{Bi}_{2} \mathrm{Se}_{3}$, 集成在 $\mathrm{Bi}_{2} \mathrm{Se}_{3}$ 层上的 MOF纳米颗粒使异质结的光电流增加了 2-3个数量级. 该混合异质结光 电探测器在 $1500 \mathrm{~nm}$ 光照下的响应度和探测度分别达 $4725 \mathrm{~A} \mathrm{~W}^{-1}$ 和 $3.5 \times 10^{13}$ Jones. 如此优异性能主要源于增强的光吸收和光门控效应的 协同作用. 本文提出的集成MOF光敏材料和 $2 \mathrm{DLM}$ 的策略为未来构建 高性能短波红外光电探测器提供了思路. 